\title{
African Linguistic Images for Cross-Cultural Communication
}

\author{
ONUORA, NGOZI THERESA \\ Alex Ekwueme Federal University Ndufu-Alike, Ebonyi State, Nigeria
}

\begin{abstract}
Cross-cultural communication takes place when message is transmitted from a person from one culture to another person from a different culture; however, communication scholars estimate that two-thirds of communications are influenced by the culture of the communication. Based on this, this paper explored socio-cultural relationships as they influence the management of communication patterns Africa. With special focus on African linguistic images, the paper analyzed the relationships between African linguistic images and the communicative powers of language, graphic systems, and the written word. Language is a means which human beings have devised for communicating ideas, feelings, emotions, desires, etc, through complex vocal or written symbols; hence, images play a central role in the complex communications that both link and separate communities and institutions.
\end{abstract}

Keywords: Cross-cultural, Linguistic, Image, Africa, Communication.

DOI: $10.7176 / \mathrm{JAAS} / 72-04$

Publication date:May $31^{\text {st }} 2021$

\section{Introduction}

Man has been expressing his thoughts and experiences through artistic forms and images. As a matter of fact, in many African societies, prior to the age of writing, images was the most reliable source of information. Early pictures, cave paintings, rock drawings, wood and bone carvings, painted ceramics etc. were the precursors of the development of writing systems. From these developed the first pictograms (pictorial symbols for words or phrases), which then led to fully fledged picture writing systems (Hoffmann, 2002). The only writing system that uses nothing but pictograms is that of the native North American prairie tribes. The expressive possibilities of such a system are very limited. Each object needs a pictogram of its own and relationships between objects can only be expressed with difficulty and indirectly. Towards the end of the 4th millennium BC, more complex writing systems emerged in the oriental city cultures. These developed, in addition to pictograms, also logograms - signs or characters with more general meanings. In Egyptian hieroglyphs, for instance, the beetle stands for "was". Thus, at a very early stage of man's history, attempts were made to present in some visible way, the thought which spoken language conveyed to the ear. Language is a unique human attribute, a distinguishing aspect of humanity. Language is a means which human beings have devised for communicating ideas, feelings, emotions, desires, etc through complex vocal or written symbols (Anigbogu, Mbah and Eme, 2001). The important communicative and symbolic qualities of language are seen in images. It is the vehicle on which communication thrives. In the opinion of Emme (2004), as cited in Enamhe (2008), modern views on art criticisms have enabled art educators to recognize that along with its formal meanings, art represents, inter alia, the culture of its maker or the culture, which provides stimulus for the art. It is therefore clear that images play a central role in the complex communications that both link and separate communities and institutions. Ndoleriire (2000) points out that language can be considered a cultural practice, and that it is both an instrument to and a product of culture. $\mathrm{He}$ further adds that 'the different languages spoken by different groups of people who have the same culture are used to express cultural norms.

Casson (1981) defines culture as 'idealised cognitive social systems of knowledge, beliefs, and value that exist in the collective minds of individual members of society. It is the mental equipment that society members use in orienting, transacting, discussing, defining, categorising, and interpreting social behaviour in their society.' It is the means by which society members generate appropriate social behaviour and appropriately interpret the behaviour of others. The development of human culture is made possible through communication, and it is through communication that culture is transmitted from one generation to another. In other words, culture and communication are intertwined (Olaniyi, 2017). Moreover, communication scholars estimate that some two-thirds of communications are nonverbal, accounting for $65 \%$ of all communication behaviours (Novinger 2008 cited in Elegbe \& Nwachukwu, 2017). These behaviours are greatly influenced by the culture of the communicator (Novinger 2008). Gudykunst and Kim (2003) emphasize that culture always affects the way interlocutors communicate, because competent speakers know what is or is not acceptable and appropriate in a given context. They know this because they have been socialised into a particular culture and have been made aware of the rules and expectations from an early stage (Olaniyi 2017).

\section{Conceptual Clarifications}

Cross-cultural Communication

Cross-cultural communication takes place when message is transmitted from a person from one culture to another 
person from a different culture. Putting meanings into words and behaviours including symbols and vice versa will differ from one person to another because of their cultural orientations. This view point is in consonance with that of Ting-Toomeys' (1999), as cited in Abdulai, Ibrahim \& Mohammed (2017) who considered intercultural communication to be "the symbolic exchange process whereby individuals from two (or more) different cultural communities negotiate shared meanings in an interactive situation." If the cultural orientation gap between the senders and receivers is wide, the differences in meanings that will accrue from the particular words and behaviours will be wide as well (Adler, 1991, as cited in Abdulai et al., 2017)). In the process, cross-cultural miscommunication does happen when the person from the second culture receiving the message does not get the sender's intended message. Cross-cultural communication never ceases to be characterized with misunderstandings emanating from misperception, misinterpretation and misevaluation as noted by Adler (1991). The chances of transmitting accurately a message gets slimmer if the sender and receiver do not share common culture of orientation lending credence to the postulation that foreigners see, interpret and evaluate things in a different way which inform their consequent acts in the contrary (Adler, 1991). Adler (1991), therefore, suggested that in approaching multicultural settings, it is imperative to assume a sense of indifference till similarity is proven. Referring to behaviours as bizarre in multicultural situations is often a symptomatic evidence of culturally based misperception, misinterpretation and misevaluation and hardly out of premeditated malice or pathologically motivated behaviour. He established then that perceptions are selective, learned, culturally determined, consistent and inaccurate. In describing images as a form of cross cultural communication, Enamhe (2008) observes that images are sometimes accorded definite meanings called icons. In communication, one just has to use icons, themes, motifs, symbols that the receiver can understand with or without the mediator. An example of this is the traditional African art where communal interpretations are firm in terms of visual concepts which makes statements (belief and ideas with motifs based on classical conventions). Going further, Enamhe (2008) explains that dialects are language-based, and they are variations of the same language having the same meaning. Accordingly, visual dialects are arts based, and when different visual images have the same meaning, they are said to share dialectical differences (e.g. the image of a pregnant woman and the image of a woman and her child does represents two dialects of the same visual language "mother and child"). Furthermore, Steele (1998) puts forward that art is used for storytelling and story making. It has a communicative function and intention and is enacted as a way to remember, celebrate, make meaning, describe, invent, or come to terms with an experience. Steele's view cuts across all dialects of visual presentations. Visual dialects can be used as a term to describe the use of elements of art or elements of design. These terms assist in interpersonal or transcultural communication.

\section{Linguistic Images and Communication}

Pictogram means a picture or shape that has a particular meaning or represents an idea. Example, the dove is a symbol of unity. A pictogram can as well mean a letter, number or sign that represent a sound, an amount, a substance, etc. A pictogram can also be seen as someone or something that people think of as representing a particular quality or idea. The snake is symbolic of evil. In the African Traditional Religion (ATR), "omu" symbolizes danger, death, sanction, keep off etc; in Christianity, the cross symbolizes Christ. "Nzu" in Igbo culture symbolizes purity. In Europe, it is the colour white that symbolizes purity. Peace is symbolized by a dove. Emmanuel Anati (Director of UNESCO World Archive of Rock Art (WARA), based on an extensive survey of several millions of pictures and engravings, attempts to demonstrate that cave paintings are indeed a kind of writing. Such carvings are regarded as universal code. They are universal code in that one can understand them without relating them to the spoken language of a particular area. This is to say that script and language are two different entities. In the words of Ricard (2007), "Africa is everywhere inscribed: from rocks to marks, sculptures, pyramids, manuscripts, etc. The continent has left graphic marks of its history everywhere."

\section{African Linguistic Images for Communication}

Graphic representation is indeed present in Africa and its existence is viewed along two schools of thought. According to Uzoagba (1978), different types of lines or strokes, shapes, forms, etc are used to evoke feelings and emotions in us; however can it be described as writing?" Speech communities always generate material means to keep and retrieve information. This according to Richard (2007) is not always writing. Reflecting, "on graphic representation of sounds and the competition generated between several systems of graphic representation," De Francis (1989) cited in Obidiebube (2011) divides students of graphic systems into two camps: the inclucivists and exclusivists using as a distinguishing criterion, their definition of writing. The view put forward two types of definition: partial writing and full writing. In the opinion of De Francis (1989), partial writing is a system of graphic symbols that can be used to convey only some thought; while full writing is a system of graphic symbols that can be used to convey any and all thought. Going by the above assertion, two groups emerge on the acceptability of what the definition of writing ought to be. The inclucivists believe that both partial and full writing should be called writing. The exclucivists believe that only full writing deserve the label. However De Francis in his "Writing Classification Scheme" classifies picture into two: non writing and writing. His non-writing includes dead-end 
symbols: cave paintings, Uruk IV symbolization, Yukaghir pictographs and Amerindian pictographs. Nsibidi, Nwagu Aneke and other indigenous scripts can fit in here because they are based on symbolization, pictographs, etc. What he classified as writing are rebus symbols syllabic systems. Nonetheless, Obidiebube (2011) disagrees with De Francis, and rather aligns with Anati (1997) attempts to demonstrate that "cave paintings are indeed a kind of writing." Anati (1977) maintains that some pictograms are ideograms and point to a universal code of graphic expression. He further adds that central Tanzania offers what is probably the longest sequence in the world of such images and probably the "cradle" of his art. Anati gave that as an exceptional testimony of the development process of thinking of intellectual achievement, and of the cultural changes that have marked East Africa within the last 40,000 years. Especially impressive are the pictures of the Kundusi gatherers, with their heads marked, arranged in a triad, as if captivated by a special myth. He further states that, painted walls stand for a cathedral. In the painted walls are kept myths and legends, that is, the capacity to keep a living relationship with the past or the future, which is usually done in palace or sanctuaries. This is likened to Yoruba panegyric poetry that offers a true historical archive, full of pictograms and ideograms, which remain to be interpreted. It provides extraordinary information on the concepts and beliefs of Bantu people. Anati (1997) attempts to relate recent finding to Nyau ritual and dance. The finding helps people to read the paintings as pictograms of masks and dance and provides a bridge to present-day Chewa society. Achebe (1958) cited in Obidiebube (2011) also employed the idea of pictogram when he presented Unoka using strokes on the wall to represent the height (amount) of his debt to his various creditors. In the traditional Igbo society, strokes were also used for bride price and also as a counting system. The highest number in Igbo traditional counting system was "nnu" four hundred. In counting things like yam, a stroke represents "nnu".

Africa is full of inscriptions. The Angolan writer Luandino Viera regards these inscriptions as "illiterate writing". Ricard (2007) maintains that paintings and engravings that encode stories and rituals belong to writing, if we adopt an inclusive position. He includes graphic symbolism as writing in a different way. The symbols are produced within speech communities and they demand interpretation by the communities. They fulfill one of the essential functions of writing: recording information and enabling its retrieval. They do this in a specialized way not available for any kind of messages. While carrying out a study on the ways to keep and retrieve information by graphic means, Raum (1943) cited in Obidiebube (2011) notes that, "when Livingstone entered the country of the Lunels, he observed that all trees along his route bore incisions, which are said to have resembled faces reminiscent of Egyptian pictures". The signs or incisions are writing because they fulfill some functions of writing, and serves as a reminder of the words, spells, and prayers of those who inscribed them. Faik-Nzuji (1992, cited in Obidiebube, 2011)) also brings to mind that, symbols are cultural creations that derive their meanings from ritual and cults, and intense moments that punctuate the life of their users. In most cases, the body is marked; objects are carved, and modeled in line with some rituals and cults in the society. People make all manner of marks on their bodies. Some of these marks are tribal like in the case of Fulani, Tiv, Igala and Yoruba people of Nigeria. The marks are used as identity and so, send a message to the viewer concerning the tribe or the nativity of the individual concerned. During the period of slavery, hot irons were used to make marks on the body of the people being horded into ships for their onward transmission into slavery in foreign lands. The marks are writings indicating their owners. "Igbu ichi" in Igbo land is not universal to every Igbo person. It is used for class differentiation to show bravery. 'Uli and Ogaru' were used to make bodily designs/marks. For example, in Okija, the bodies of women taking the "Eze Nwaanyi" title are designed with those substances during the "Ipu ahia" market outing ceremony. Marks are also made on yams while they are still forming under the soil. Individual farmers have their marks or logo, which they carve into the yam as a mark of identity when eventually the yams are harvested. Raum (1943) referred to marking of property as "crystallizing and registering thought processes."

Marking of property as well as graphics and coloured symbols, are used by African people. As pointed out by Obidiebube (2012), they serve the following purposes:

i. The perpetuation of expressions of emotional states and volitional tendencies in inscriptions, which bear a magical and sometimes religious significance.

ii. The regulations of social relations by supplying distinguishing marks for private clan property and it also afford a medium of communication between individuals.

iii. Graphic images serve to record the shape, name and number of objects as well as subjects of conversations and negations and thus, act as instrument of intellectual processes.

Obidiebube (2012) further avers that graphic images fulfill different functions: magical and numerical. Certain systems have been particularly well perfected.

\section{Models of Graphic Systems in Africa}

Discussing writing and graphics systems in Africa, Kreamer, Roberts, Harney \& Purpura (2007) mention that the Ge'ez script - also known as Ethiopic - has been in continuous use for more than two millennia. It is distantly related to Sabaean, an alphabet brought to Abyssinia (ancient Ethiopia) from Arabia around the sixth century BCE. Christian Ethiopians in the fourth century CE, intent on writing the Ge'ez language, developed the script into a 
distinctive syllabary, an alphabet in which each symbol represents a syllable made of a consonant and a vowel. Although Ge'ez ceased to be a commonly spoken language by the thirteenth century, it continues to be used as the liturgical language of the Ethiopian Orthodox Church. It was later adapted to write other Ethiopian languages, including Amharic, now the national language of contemporary Ethiopia. The ecclesiastical arts of Ethiopia combine word and image to create aesthetically powerful objects of healing and devotion, such as illuminated manuscripts, icons and prayer scrolls.

In the same vein, Kreamer, et al. (2007) assert that Nsibidi is an ancient system of graphic communication indigenous to the Ejagham peoples of southeastern Nigeria and southwestern Cameroon in the Cross River region. It is also used by neighboring Ibibio, Efik, and Igbo peoples. Aesthetically compelling and encoded, Nsibidi does not correspond to any one spoken language. It is an ideographic script whose symbols refer to abstract concepts, actions, or things and whose use facilitates communication among peoples speaking different languages. Though it is enjoyed as an artistic practice by the general public, deeper knowledge of the nearly 1000 nsibidi symbols is restricted to members of men's associations that once controlled interethnic trade and maintained social and political order in the region. The use of Nsibidi was popular among secret societies like Mmonwu, Ekpe and Okonko whose members would not want to discuss the Nsibidi publicly. Afigbo (1975, cited in Obidiebube, 2011)) rightly observes that, the ability to write Nsibidi required formal education.

Nsibidi signs can be drawn in the air (as gestures) or on the ground, as well as on skin (as tattoos), houses, and art forms, such as masks and textiles. Like many other African writing systems, nsibidi is often used to mediate social relationships rather than to simply document ideas and information. The beginnings of Nsibidi and some other forms of writing in Africa are shrouded in mythology (Nwadike, 2002).

In the nineteenth and twentieth centuries, remarkable individuals invented a number of African scripts as a direct response to the European presence in Africa. King Ibrahim Njoya, for example, who was the ruler of the Bamum people in the Grassfields region of what is now Cameroon, invented the Bamum script in 1896. Although likely influenced by Arabic and by Liberia's Vai script, both of which were already used in the region, King Njoya was inspired by a dream to create an original form of writing for his people. The first version of Bamum contained more than 400 pictographic and ideographic characters. King Njoya continued to revise the script, and by 1903 he had reduced it to a phonetic syllabary of about eighty signs. Taught at schools and used prominently at the royal court, the Bamum script was employed by King Njoya and his subjects to fulfill bureaucratic and political ends in ways similar to their European contemporaries' use of writing. More importantly, the script was used to compile the kingdom's history, to record court rules, and to document local customs and knowledge.

In Africa as throughout the world, the decorated body communicates information to those versed in its visual vocabulary. Scarification and tattooing have long been viewed as marks of civilization denoting human ideals. They are employed to affirm ethnic identity, to indicate rank or standing within society, and to signal permanent transition to adulthood and responsibility. As tactile registers, scarification signifies the cultivation of the body for adulthood, marriage, and birth. Works of art from the Baule, Kongo, Bembe, and Luba reflect a range of complex scarification practices across west and central Africa. Just as bodies are transformed, idealized, and rendered semantically rich through scarification and tattooing, many objects used in Africa-such as vessels and pyroengraved gourds - are modeled in relief or incised with graphic patterns imitating those on the skin. Such objects serve as metaphorical bodies, reinforcing deeply held cultural beliefs about what it means to be human. Other types of inscribed objects are worn on the body to enhance the wearer's identity or aura. These include talismanic pendants and rings, some with geometric patterns inscribed in Arabic; others with artists' signatures in Tifinagh, an ancient Tuareg script. Contemporary works by Berni Searle, Ghada Amer, and Iké Udé explore the body as a canvas for inscription. South African artist Searle works with henna dyes to explore the shifting and complex meanings of the word "stain," and Iké Udé recalls the practice of uli body and wall motifs of his Igbo heritage to explore the interplay of form and script, high fashion and the anonymous, disembodied self.

In religious traditions the world over, writing and graphic inscription are endowed with sacred attributes, because they are considered as both the embodiment of the divine, and a powerful means for conveying religious teachings. Inscribed works of art communicate meaning through the visual language of objects as well as the mystical powers and attributes of words, letters, images, and the very act of writing. Three inscription systemsEgyptian hieroglyphics, the liturgical language of Ge'ez in Ethiopia, and Arabic, used in much of Africa-are typical examples.

Pictographs have been enriched by what De Francis (1989) describes as rebus principle. He states that pictographs used as pictographs leads nowhere. It is only pictographs used as phonetic symbols that lead to full writing. The rebus principle formed the basis of three systems of writing, generally thought to have been independently developed, which were created at intervals of about fifteen hundred years (1500). The writing systems are: by the Sumerians (3000BC), the Chinese (1500BC), and the Meyas about the beginning of our era. De Francis (1989) demonstrates convincingly that Chinese ideograms note essentially the sounds of syllables while Egyptian hieroglyphs note the sounds of consonants. Note that "not all the system is phonetically based but it has a central phonetic component and it is precisely this that makes it capable of recording any kind of thought." This 
is what makes it a full writing. The operation of the "rebus principle" substituting images of things to represent the sounds of their names is the key to the development of a writing system. Pictograms serve to complete the picture, to enrich, and to make the texts precise. The oldest written African language is thus Egyptian, to which we can add Nubian (Obidiebube, 2012). The Meroe pyramids and the Sudan desert have yielded stones with inscriptions, allowing us to decipher Merioritic script but not to understand the language. Many African languages have been written with inadequate systems. Perhaps, Meroe was the first one of the series and this is the cause of its present opacity. Opacity means the quality of being difficult to understand. Ricard (2007) observes that, in Africa, only Egyptian, Nubian, Ge'ez and Tamazight have over the centuries, developed their own systems of full writing. Ricard further explains that the Ethiopian syllabry is the only syllable still in practical use in Africa today. Other African languages, according to him, have borrowed scripts, whether Arabic or Roman. Arabic itself was probably the most commonly used written language in Africa up to the nineteenth century. It was written in Timbuktu in the fifteenth century. There still exists Arabic literature in West Africa. For instance, in Nigeria today, the Moslem Koran is still being written in Arabic script. Ricard further informs that it is important for people to note that "to borrow a script is not to borrow a language, and some adoptions are necessary (Obidiebube, 2012).

\section{Conclusion/Recommendation}

There is no gainsaying that the visual impact of images or the graphic systems is as significant — in some instances, even more so - as the literal meanings that they convey. Its creative use in the constructions of identity and relations of power; the play between form and meaning; the intrinsic connections of some forms of inscription to the sacred; the reconfiguring of text as political commentary all point to the fact that African linguistic images have always plated effective role in communication. Thus, if all the African languages are put into writing, it will help the languages not to go into extinction. The languages will develop into languages of official communication within their areas thereby, giving identity to the owners of the languages. African symbols, paintings, carvings, marks, pictograms and other forms of script should be developed and preserved and also be regarded as forms of writing.

\section{References}

Abdulai, M., Ibrahim, H. \& Mohammed, M. A. (2017). Communicating across Cultures in Multinational Ibis West Africa. International Journal of Intercultural Relations, 58, $42-53$.

Anagbogu, P.W.N., Mbah, B. M. \& Eme, C.A. (2001). Introduction to Linguistics. Awka: J.F.C.

Anati, E. (1997). L’art Rupestre Dans le Monde. Imaginarie de la Prehistoire. Paris: Larouse.

De Francis, J. (1989). Visible Speech: The Diverse Oneness of Writing Systems. Honolulu: University of Hawaii Press.

Enamhe, B. (2008). Visual Arts: the Hub in the Wheel of Communication. Global Journal of Humanities, 6(1\&2).

Gudykunst, W. \& Kim, Y. (2003). Communicating with strangers: An approach to intercultural communication (4th ed.). Boston: McGraw-Hill.

Hoffmann, V. (2002). Picture Supported Communication in Africa. Weikersheim: Margraf Verlag.

Kreamer, C. M., Roberts, M. N., Harney, E. \& Purpura, A. (2007). Inscribing Meaning: Writing and Graphic Systems in African Art. Africa Arts, http://www.mitpressjournals.org/doi/pdf/10.1162/afar.2007.40.3.78.

Nwadike, I.U. (2002). Igbo Language in Education: An Historical Study. Obosi: Pacific.

Obidiebube, J. I., (2011). Concept of African script: Pre-colonial, Colonial and Modern Periods. Knowledge Review, 22(2).

Olaniyi, K. (2017). Politeness Principle and Ilorin Greetings in Nigeria: A Sociolinguistic Study. International Journal of Society, Culture and Language, 5(1), 58-67.

Raum, O.F. (1943). The African chapter in the history of writing. In Ricard A. (1995) (ed.). Literature of Africa Noire. Paris: Karthala.

Ricard, A. (2007). Africa and writing. In Olaniyan, T. \& Quayson (eds.). African Literature: An Anthology of Criticism and Theory. USA: Blackwell.

Steele, B. (1998). Draw me a story: An Illustration Exploration of Drawing as a Language. Winipeg: M. W. Pegus Publishers.

Udechukwu, G. I., (2019). The Significance and Use of Cultural Symbols in the Contemporary African Society: Igbo Symbols as a Paradigms. Mgbakoigba, Journal of African Studies, 8(1).

Uzoagba, I.N. (1978). Understanding Art in Education. Aba: Awa \& Co. press. 